Review Article

\title{
A REVIEW ON URSOLIC ACID: A NATURALLY OBTAINED PENTACYCLIC TRITERPENE
}

\author{
NARGEES SHAIKH ${ }^{1 *}$, GAURANG SAWANT ${ }^{1}$, NIKHIL DIXIT $^{1}$ \\ ${ }^{1}$ Department of Pharmaceutics, H. K. College of Pharmacy, Oshiwara, Mumbai, India \\ "Email: nargeesnaaz34@gmail.com
}

Received: 17 Oct 2020, Revised and Accepted: 20 Apr 2021

\section{ABSTRACT}

Natural products derived from plants have been used for decades in traditional medicine. Many classes of compounds exist in plants such as saponins, alkaloids, anti-oxidants, etc. Pentacyclic triterpenes are also one of the compounds occurring in plants. In this class Ursolic acid is a wellrecognized compound that is available from various sources like seeds as well as fruits and possess many types of activities and is a bright contender for developing novel treatment approaches for treating diseases.

Keywords: Natural, Traditional, Triterpene, Ursolic acid

(c) 2021 The Authors. Published by Innovare Academic Sciences Pvt Ltd. This is an open access article under the CC BY license (https://creativecommons.org/licenses/by/4.0/) DOI: https://dx.doi.org/10.22159/ijpps.2021v13i6.41106. Journal homepage: https://innovareacademics.in/journals/index.php/ijpps.

\section{INTRODUCTION}

Secondary metabolites are natural commodities that many times possess ecological importance in maintaining the collaborations between plants and their environment. They can have many different roles such as defensive substances which include phytoalexins and phytoanticipins, antifeedants, attractants, and pheromones [1]. The significance of plant secondary metabolites in medicine, agriculture, and industry has shown the light to many research work regarding their synthesis, biosynthesis, and biological activity. It has been predicted that a not less than $40 \%$ of medicines have their sources in these active natural commodities [2]. A pivotal group of natural products consists of terpenes and their derivatives. A group of terpenes that are becoming popular recently is the pentacyclic triterpenoids. Ursolic acid (UA) is a pentacyclic triterpenoid having a molecular weight of $456.68 \mathrm{~g} / \mathrm{mol}$ and a melting point of $283-285^{\circ} \mathrm{C}$, which falls in the class of C30 isoprenoid compounds. These compounds are extensively available in nature; hence, UA can be extracted from many plants, for example, Calluna vulgaris(heather), Rosmarinus officinalis (rosemary), Calendula officinalis (marigold), Melaleuca leucadendron (melaleuca), Malusdomestica (apple), Origanum vulgare (oregano), Salvia officinalis(sage), Origanum majorana (marjoram), Lavandula angustifolia(lavender flowers), Thymus vulgaris (thyme) and Eucalyptus(eucalyptus) [3, 4]. The existence of UA in almost all medicinal herbs and fruits makes it a part of human food [5]. The biosynthesis of UA and other isoprenoid compounds present in plant tissues begins from the cyclization of squalene into (3S)-oxidosqualene, which can synthesize over 80 different carbon skeletons through the activity of oxidosqualene cyclase enzymes that undergo the carbocation rearrangements responsible for this biological variety [6]. The common precursor (3S)oxidosqualene is transformed into the dammarenyl ring and oleanyl cation that further proceeds towards ring expansion and other cyclization reactions to make the specific fifth ring which exists in lupeol, $\alpha$-amyrin, and $\beta$-amyrin skeletons as shown in fig. 1 . The $\alpha$ amyrin showcases the UA skeleton, whereas its C30 isomer, $\beta$-amyrin showcases the skeleton of the oleanolic acid (OA) [7]. The crystalline solidified compound, chemically known as 3bhydroxy-urs-12-en-28oic acid, has been employed for ages in traditional medicine for its medicinal activities [8]. Lately, the search for biologically active substances from natural sources has boosted interest in its investigation. Studies show that UA has many pharmacological activities, including anti-inflammatory, hepatoprotective, antitumor, cardioprotective, neuroprotective, antimicrobial, antihyperlipidemic antidiabetic, antifungal, antiviral, and trypanocidal [9]. But, it is classified as a class IV drug in the Biopharmaceutics Classification System thanks to its restricted pharmacological effects because of low solubility in water and problems in permeating biological membranes [10]. Thus, novel approaches have been inaugurated to boost the biopharmaceutical properties of this compound, specifically by employing new drug delivery technologies. Several UA delivery systems have been formulated without fail, including nanoemulsions [10], mesoporous silica nanoparticles containing silica [11], solid lipid nanoparticles [12], liposomes [13], niosomal gels [14], and solid dispersions [15] which comprise of all the studies conducted. Herein, a literature survey was performed using accessible databases such as Google Scholar, PubMed, and Scopus to review research articles and thus compile a concise review regarding an introduction to ursolic aid along with its pharmacological activities and applications.

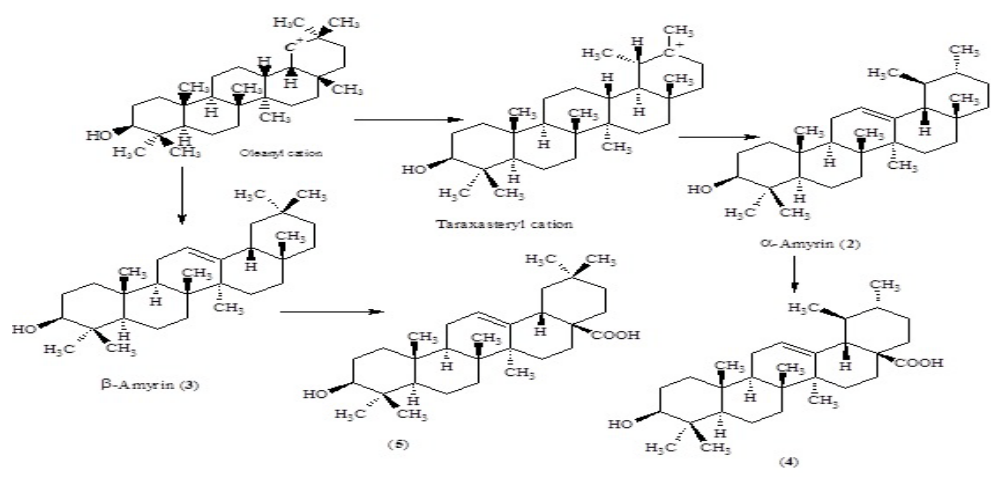

Fig. 1: Biosynthesis of ursolic Acid (4) from oleanyl cation, adapted from reference [7], Copyright Obtained by Permission 


\section{Sources}

Triterpenoids have been outlined in a diversity of common European plants and fruits [16-18]. UA (3ß-hydroxyurs-12-en-28oic) is a pentacyclic triterpene and a phytosterol as shown in fig. 2 . Triterpenes are largely obtained from vegetable oils, vegetarian foods, medicinal herbs, cereals, as well as fruits. A predicted human utilization of triterpenes was estimated to $250 \mathrm{mg}$ per day in the developed countries. Whereas in Mediterranean countries, where most of the food consumed consists of olive oil, the mean consumption of triterpenes by a person can reach $400 \mathrm{mg} / \mathrm{kg} /$ day due to the high content of olive oil [5].

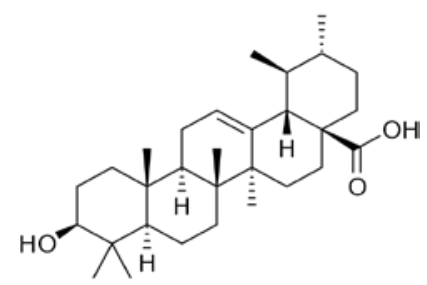

Fig. 2: Structure of ursolic acid

Lately, there is an unimaginable interest in triterpenes. The majority of the researches were concentrated on the cholesterol-lowering properties of triterpenes. UA is widely available especially in higher plants e. g. Rosmarinus officinalis, Glechoma hederaceae, Ilex paraguariensis, Ichnocarpus frutescens, Phoradendron juniperinum, Syzygium claviflorum, Hyptis capitata [19-22]. It is a component of many herbal medicines sold in Asia and worldwide for inflammatory conditions [23]. Among berries, North American cranberry fruit (Vaccinum macrocarpon), specifically consists of a considerable quantity of UA in its peel. It is present in the aglycone configuration as well as the cis and trans-p-hydroxyl cinnamate esters [24]. The quantitative examination of cranberry fruit and products by utilizing liquid chromatography-mass spectrometry (LC-MS) showed the UA content of whole cranberry fruit of a variety of cultivars to fall in between 60 to $110 \mathrm{mg}$ per $100 \mathrm{~g}$ of fresh fruit [25]. A not so different content was established in sweetened, dried fruit. As a contrast, less UA was found in the gel of cranberry sauce or commercial cranberry juice may be attributed to its low solubility in water [26]. Sea buckthorn (Hippophae rhamnoides L.) is an industrially grown berry in northern Europe. The phytochemical examination demonstrated that UA was present in much more quantity in buckthorn berry extract when compared against other berries [27]. Also, Fang and Mc Laughlin have extracted UA from red berries of the decorative shrub winterberry (Ilex verticilata) [28]. Winterberry is not advised for human diet (USDA/NRCS plant fact sheet) [29]. UA, OA, and their derivatives have been announced in non-berry fruits including apple (Malus pumila). aglycones as well as many cinnamoyl and hydroxycinnamoyl esters of UA and OA were extracted from apple peels [30]. Table 1 shows the content of ursolic acid present in various fruits, vegetables, and spices.

Table 1: Various sources of ursolic acid along with the quantity present within each

\begin{tabular}{llll}
\hline Biological sources & Scientific name & Amount present in milligrams/100g & References \\
\hline Apple Peel & Malus pumila & 152 & {$[30]$} \\
Balsam Pear & Momordica charantia & $42 \pm 5$ & {$[31]$} \\
Brown Mustard & Brassica juncea & $14 \pm 5$ & {$[31]$} \\
Star Fruit & Averrhoa carambola & $13 \pm 4$ & $12 \pm 2$ \\
Guava & Psidium guajava & 520 & {$[31]$} \\
Mahogany & Swietenia macrophylla & $19.2-192$ & {$[31]$} \\
Daylily & Hemerocallis sp & {$[31]$} \\
Damnacanthus & Damnacanthus indicus & $57 \pm 8$ & {$[31]$} \\
Hawthorn & Crataegus & {$[32]$} \\
\hline
\end{tabular}

\section{Pharmacological activities}

\section{Anti-inflammatory activity}

Nuclear factor-kappa B (NF-kb) is a major cell signaling pathway held accountable for the maintenance of inflammatory effects genes expression [34]. The assessment of anti-inflammatory effects of UA by exposing BALB/c mice to ovalbumin for asthma induction showed that UA stops NF-kB, and thus can be adopted in the treatment of asthma [35]. Checker et al. saw that UA showed antiinflammatory activity in a mouse model by halting the production of cytokines by T cells, B cells, and macrophages, via squashing of the transcription factors NF-kB, nuclear factor of activated T cells, as well as activator protein-1 [36].

\section{Antitumor activity}

In a study, UA demonstrated potential in the prevention and treatment of cancer by modulating several cell signaling enzymes and shielding against carcinogenic agents [37]. The treatment of breast cancer cells with UA at low doses (5-20 mmol) led to a G21/G1 cell cycle arrest, an elevation inp21 levels, oxidative stress, and Deoxyribosenucleicacid (DNA) damage at $20 \mathrm{mmol}$, UA brought about autophagy as well as apoptosis of breast cancer cells without damaging the normal cells [38]. Furthermore, UA boosted photo toxicity of ultraviolet to visible light broadband radiation by changing the triggering mechanism of Tumor Protein P53 and NF-kB in melanoma cells [39].

\section{Hepatoprotective activity}

The hepatoprotective effect of UA alone or in conjunction with other active ingredients on acute and chronic liver injury is well recognized [40]. Guti_errez-Rebolledo et al. demonstrated that the subcutaneous administration of an amalgamation of $\mathrm{UA}$ and $\mathrm{OA}$ in male BALB/c mice with hepatic injury induced by anti-tubercular agents lead to a reduction in aspartate transaminase as well as alanine aminotransferase levels and enhancement in histological changes in the liver [41]. UA stopped the advancement of nonalcoholic fatty liver disease, with attenuation in liver weight and hepatic steatosis, in addition to amassing of intracellular lipids, possibly due to a boosting of lipid $\beta$-oxidation as well as halting of hepatic stress [42]

\section{Cardioprotective activity}

Cardiovascular disorders are one of the major reasons for mortality and morbidity worldwide. UA is helpful in the treatment of cardiovascular diseases. Liobikas et al. assessed the effect of UA on mitochondria extracted from mouse hearts and assessed whether this compound encouraged the decoupling of oxidative phosphorylation in the mitochondria without bringing changes in the respiration rate, besides halting Hydrogen Peroxide (H2O2) production [43]. Also, the use of UA in the treatment of myocardial fibrosis and hypertrophy in experimental models in vitro and in vivo showed the reduction of fibrosis and cardiac hypertrophy, which may occur via the inhibitory mechanism of the microRNA-21 (miR21)/extracellular-signal-regulated kinase (ERK) signaling pathways in the myocardial cells [44].

\section{Neuroprotective activity}

Some studies have demonstrated the well-organized neuroprotective effect of UA. It can control inflammatory responses in the ischemic brain of rats, which was shown by a considerable deduction in infarct size as well as a reduction in lipid peroxidation 
via the activation of the nuclear factor-erythroid 2-related factor 2 (Nrf2) [45]. In the study carried out by Ding et al. the adoption of UA for the treatment of brain lesions in a murine model considerably enhanced cerebral edema as well as neurological problems attributed to trauma along with a reduction in oxidative stress. This study showed that the neuroprotective effect of UA is connected with the activation of the Nrf2 pathway [46].

\section{Antimicrobial activity}

In a study carried out by Singh et al. UA demonstrated antimycobacterial activity against Mycobacterium smegmatis, Mycobacterium tuberculosis, and clinically removed multi-drugresistant $M$. tuberculosis at a minimum inhibitory concentration (MIC) of $62.5 \mathrm{mg} / \mathrm{ml}$ [47]. Nascimento et al. [48] assessed the effect of UA and its derivatives on the vulnerability of certain pathogenic bacteria to antibiotics that fall in the aminoglycosides class (neomycin, amikacin, kanamycin, and gentamicin). 3b-Formyloxyurs-12-en-28-oic acid used at a concentration of $64 \mathrm{mg} / \mathrm{ml}$ adopted in conjunction with kanamycin showed a synergistic effect against $\mathrm{E}$. coli, causing a massive reduction in MIC from $128 \mathrm{mg} / \mathrm{ml}$ to 8 $\mathrm{mg} / \mathrm{ml}$.

\section{Antihyperlipidemic activity}

A few studies on the antihyperlipidemic effect of UA have been done. The adoption of UA and artesunate in the treatment of hyperlipidemia in rabbits showed that the triglycerides were decreased by the two compounds acting individually. But, when used in combination, they considerably reduced cholesterol and triglyceride levels in addition to hepatic steatosis and aortic root lesions thus providing additional benefits as contrast when using individually [49].

\section{Antidiabetic activity}

The antidiabetic property of UA has been assessed in vivo experimental models for type 2 diabetes. The hepatic insulin resistance was boosted by bringing changes in the fatty acid, Tumor Necrosis Factor Alpha (TNF- $\alpha$ ), as well as adiponectin levels, which boosted Peroxisome Proliferator-Activated Receptor Alpha (PPAR$\alpha$ ) expression and as a result the adjustment of Phosphoenolpyruvate Carboxykinase (PEPCK) protein as well as phosphorylation of insulin receptor substrate-2 [50]. The antihyperglycemic effect of UA in hyperglycemic rats was brought about by insulin secretion and insulin imitative effect on glucose uptake by UA in addition to synthesis as well as translocation of Glucose Transporter type 4 (GLUT4) [51].

\section{Antifungal activity}

A study carried out by Mahlo et al. UA with MIC of $20-250 \mathrm{mg} / \mathrm{ml}$ demonstrated antifungal activity against Aspergillus niger, Aspergillus parasiticus, Colletotrichum gloeosporioides, Trichoderma harzianum, Penicillium expansum, Penicillium janthinellum as well as Fusarium oxysporum [52]. At varying concentrations (500, 750, and $1000 \mathrm{ppm})$, UA also considerably halted $(\mathrm{P}<0.001)$ the spore release of Alternaria alternata, Cochliobolus lunata, Fusarium moniliforme, Fusarium pallidoroseum, and Helminthosporium [53].

\section{Anti-viral activity}

Zhao et al. assessed the anti-viral effect of UA against cytomegalovirus and compared that to that of two other drugs, namely ganciclovir and jinyebaidu (control) [54]. The Results concluded that the antiviral activity of UA is considerably more powerful than that of ganciclovir or jinyebaidu. In another study, UA showed anti-HCV (hepatitis $C$ virus) activity through the reduction of Hepatitis $\mathrm{C}$ virus nonstructural protein RNA dependent (HCV NS5B RdRp) activity by acting as a noncompetitive inhibitor [55].

\section{Trypanocidal activity}

UA showed in vitro trypanocidal effect which was demonstrated by an IC50 value of $25.5 \mathrm{mmol}$ and $77 \%$ trypomastigote lysis at a concentration at $128 \mathrm{mmol}$. In the in vivo assay studies that were carried out in mice, the administration of UA at $20 \mathrm{mg} / \mathrm{kg} /$ day considerably reduced the parasitemia [10].

\section{Applications in drug delivery systems}

As discussed above UA demonstrates many pharmacological activities. However, it has less solubility in water which translates to its bioavailability and therapeutic suitability, because the solubility and polarity of a compound can determine its ability to penetrate biological membranes $[56,57]$. Various methods can be utilized to bypass these shortcomings, such as particle size reduction, salt formation, chemical changes in the molecules, usage of surfactants, adjusting the $\mathrm{pH}$, or addition of the drug into various delivery systems [58]. Drug delivery systems have been adopted with great accomplishments to enhance the physicochemical properties of UA as well as favor its therapeutic application. They also change the drug release besides boosting solubility and enhance the bioavailability of hydrophobic drugs such as Nanoparticles and other Nano drug delivery strategies [59-63]. In a study performed by $\mathrm{Li}$ et al. pH-sensitive mesoporous silica nanoparticles were established to be biocompatible and permitted sustained release of UA, besides improving the cytotoxic effect against human hepatocellular carcinoma cells (HepG2), when compared against free UA [11]. Vargas de Oliveira et al. [10] assessed the trypanocidal effect, cytotoxicity and in vitro dissolution profile of UA administered by the nanoemulsions (constituted by purified water, Capryol_90 and Cremophor__EL/Transcutol_ P) and studied the enhancement in the drug dissolution profile. UA release was observed to be 3.75 times greater and 24 times more rapid when compared against a physical mixture in an alkaline dissolution medium, which showed the significance of emulsification in improving the presence of the drug in the dissolution medium. Topical formulations were also adopted due to their advantages over the oral route, such as no gastrointestinal effects, decreased renal toxicity, and higher patient compliance $[64,65]$. Transdermal niosomal gels of UA formulated for the treatment of arthritis ensured in a vesicle size of $665.45 \mathrm{~nm}$, drug entrapment efficiency of $92.74 \%$, and considerably better in vivo results when compared against oral formulation and traditional gel system of UA.[14] Solid dispersions can also be a promising approach for the administration of UA because these, consist of molecular fusions of hydrophobic drugs with carriers that are either water-soluble or soluble in both water and organic solvents, which also provides a reduction of drug particle size thereby leading to an enhancement in the solubility and change the drug release profile [66]. An experiment done by Eloy and Marchetti to assess the impact of hydrophilic carriers (PEG 6000 and Poloxamer 407) as well as the method of preparation (fusion and solvent) of solid dispersions for aqueous solubility of UA demonstrated that Poloxamer 407 boosted the solubility as well as dissolution rate of the drug in solid dispersions more accurately than PEG 6000 owing to their surfactant properties. Also, the solvent method for preparing solid dispersions was more superior when compared against the fusion method for enhancing drug solubility [15].

\section{CONCLUSION}

All plants are useful in one or the other ways. They produce very important compounds which play a very important role either as food, nutraceuticals, or showing therapeutic activity. Triterpenes are consist of five rings fused and are synthesized within the plants from Squalene. Ursolic acid is a very versatile compound and shows a variety of activities which have been discussed. It is mostly isolated from plants and their components such as fruits and berries where it is present in different chemical forms. Ursolic acid has bioavailability and solubility problems and hence new drug delivery strategies were taken up to solve this problem with many of them exhibiting excellent results. It also represents a promising candidate for developing more effective drug delivery systems and also helping it unleash its full potential for the treatment of diseases.

\section{ACKNOWLEDGMENT}

The authors are thankful to the staff of H. K. College of Pharmacy for guiding the preparation of this manuscript.

\section{FUNDING}




\section{AUTHORS CONTRIBUTIONS}

All authors have taken part in the design and drafting of the article and revising it critically for important intellectual content as well as approval of the final version.

\section{CONFLICT OF INTERESTS}

Declared none

\section{REFERENCES}

1. Hanson JR. The biosynthesis of secondary metabolites. In: Natural products, the secondary metabolites. The Royal Society of Chemistry: Cambridge UK; 2003. p. 112-21.

2. Gershenzon J, Kreis W. Biosynthesis of monoterpenes, sesquiterpenes, diterpenes, sterols, cardiac glycosides and steroid saponins. In: Biochemistry of plant secondary metabolites. Annual plant reviews. Wink M. Ed. Vol. 2. Sheffield Academic Press: Sheffield, UK; 1999. p. 222-99.

3. Liu J. Oleanolic acid and ursolic acid: research perspectives. J Ethnopharmacol 2005;100:92-4.

4. Wozniak L, Skąpska S, Marszałek K. Ursolic acid-a pentacyclic triterpenoid with a wide spectrum of pharmacological activities. Molecules 2015;20:20614-41.

5. Moreau RA, Whitaker BD, Hicks KB. Phytosterols, phytostanols, and their conjugates in foods: structural diversity, quantitative analysis, and health-promoting uses. Prog Lipid Res 2002;41:457-500.

6. Ebizuka Y, Katsube Y, Tsutsumi T, Kushiro T, Shibuya M. Functional genomics approach to the study of triterpene biosynthesis. Pure Appl Chem 2003;75:369-74.

7. Babalola IT, Shode FO. Ubiquitous ursolic acid: a potential pentacyclic triterpene natural product. J Pharmacogn Phytochem 2013;2:214-22.

8. Kashyap D, Tuli HS, Sharma AK. Ursolic acid (UA): a metabolite with promising therapeutic potential. Life Sci 2016;146:201-13.

9. Eloy JO, Saraiva J, Albuquerque SD, Marchetti JM. Preparation, characterization and evaluation of the in vivo trypanocidal activity of ursolic acid-loaded solid dispersion with poloxamer 407 and sodium caprate. Braz J Pharm Sci 2015;51:101-9.

10. Vargas de Oliveira EC, Carneiro ZA, de Albuquerque S, Marchetti JM. Development and evaluation of a nanoemulsion containing ursolic acid: a promising trypanocidal agent. AAPS PharmSciTech 2017;18:2551-60.

11. Li T, Chen X, Liu Y, Fan L, Lin L, Xu Y, et al. pH-sensitive mesoporous silica nanoparticles anticancer prodrugs for sustained release of ursolic acid and the enhanced anti-cancer efficacy for hepatocellular carcinoma cancer. Eur J Pharm Sci 2017;96:456-63.

12. Nahak P, Karmakar G, Chettri P, Roy B, Guha P, Besra SE, et al. Influence of lipid core material on physicochemical characteristics of an ursolic acid-loaded nanostructured lipid carrier: an attempt to enhance anticancer activity. Langmuir 2016;32:9816-25

13. De Araujo Lopes SC, Novais MVM, Teixeira CS, Honorato Sampaio KS, Perreira M, et al. Preparation, physicochemical characterization, and cell viability evaluation of longcirculating and $\mathrm{pH}$-sensitive liposomes containing ursolic acid. Biomed Res Int 2013;2013:1-7.

14. Jamal M, Imam SS, Aqil M, Amir M, Mir SR, Mujeeb M. Transdermal potential and anti-arthritic efficacy of ursolic acid from niosomal gel systems. Int Immunopharmacol 2015;29:361-9.

15. Eloy JO, Marchetti JM. Solid dispersions containing ursolic acid in poloxamer 407 and PEG 6000: a comparative study of fusion and solvent methods. Powder Technol 2014;253:98-106.

16. Fernandes AS, Baker EA, Martin JT. Studies on plant cuticle: VI. The isolation and fractionation of cuticular waxes. Ann Appl Biol 1964;53:43-58.

17. Kristo TS, Terdy PP, Simandi B, Szoke, Lemberkovics E, Kery A. Efficiency of supercritical fluid extraction for the production of non-volatile terpenoids from taraxaci radix. Acta Pharm Hung 2001;71:318-24.

18. Brieskorn $\mathrm{CH}$, Suss HP. Die triterpenoide der birnen-und apfelschale. Arch Pharm 1974;307:949-60.
19. Gnoatto SCB, Dassonville-Klimpt A, Da Nascimento S, Galera P, Boumediene K, Gosman G, et al. Evaluation of ursolic acid isolated from Ilex paraguariensis and derivatives of aromatase inhibition. Eur J Med Chem 2008;43:1865-77.

20. Pandurangan A, Khosa RL, Hemalatha S. Chemical studies on the roots of ichnocarpus frutescens. Sch Res J 2010;2:222-4.

21. Kashiwada $Y$, Nagao $T$, Hashimoto A, Ikeshiro $Y$, Okabe $H$, Consentino LM, et al. Anti-AIDs agents anti-HIV activity of 3-0acyl ursolic acid derivatives. J Nat Prod 2000;63:1619-22.

22. Bumuamba K, Gammon DW, Meyers P, Marie-Gere Veve, Dijoux Franca MG, Scoth G. Antimycobacterial activity of plant species used as traditional medicines in the Western cape province (South Africa). J Ethnopharmacol 2008;117:385-90.

23. Kim KA, Lee JS, Park HJ, Kim JW, Kim CJ, Shim IS, et al. Inhibition of cytochrome P450 activates by oleanolic acid and ursolic acid in human liver microsomes. Life Sci 2004;74:2769:79.

24. Murphy BT, MacKinnon SL, Yan X, Hammond GB, Vaisberg AJ, Neto CC. Identification of triterpene hydroxycinnamates with in vitro antitumor activity from whole cranberry fruit (Vaccinium macrocarpon). J Agric Food Chem 2003;51:3541-5.

25. Kondo M. Phytochemical studies of extracts from cranberry (Vaccinium Macrocarpon) with anticancer, antifungal and cardioprotective properties: a thesis in chemistry (Doctoral dissertation, University of Massachusetts Dartmouth); 2006. p. 250.

26. Neto CC. Berries and cancer prevention. Springer Science and Business Media. Chap. 2; 2011. p. 41-9.

27. Grey C, Widen C, Adlercreutz P, Rumpunen K, Duan RD. Antiproliferative effects of sea buckthorn (Hippophae rhamnoides L.) extracts on human colon and liver cancer cell lines. Food Chem 2010;120:1004-10.

28. Fang XP, Mc Laughlia JL. Ursolic acid, a cytotoxic component of the berries of Ilex verticillata. Fitoterapia 1989;61:176-7.

29. USDA/NRCS plant fact sheet. Available from: http://plants.usda.gov/factsheet/pdt/fs_live.pdf [Last accessed on 10 Jan 2021]

30. He X, Liu RH. Triterpenoids isolated from apple peels have potent antiproliferative activity and may be partially responsible for apple's anticancer activity. J Agric Food Chem 2007; 55:4366-70

31. Yin MC, Lin MC, Mong MC, Lin CY. Bioavailability, distribution, and antioxidative effects of selected triterpenes in mice. J Agric Food Chem 2012;60:7697-701.

32. Cai YF, Huang QS. Determination of oleanolic acid and ursolic acid in Damnacanthus indicus from different places by RPhPLC. J Chin Med Mater 2012;35:694-6.

33. Lin $Y$, Vermeer MA, Trautwein EA. Triterpenic acids present in hawthorn lower plasma cholesterol by inhibiting intestinal ACAT activity in hamsters. Evid Based Complement Alternat Med 2011. DOI:10.1093/ecam/nep007

34. Tuli HS, Chaudhary P, Beniwal V, Sharma AK. Microbial pigments as natural color sources: current trends and future perspectives. J Food Sci Technol 2015;52:4669-78.

35. Kim SH, Hong JH, Lee YC. Ursolic acid, a potential PPARy agonist, suppresses ovalbumin-induced airway inflammation and Penh by down-regulating IL-5, IL-13, and IL-17 in a mouse model of allergic asthma. Euro J Pharmacol 2013;701:131-43.

36. Checker R, Sandur SK, Sharma D, Patwardhan RS, Jayakumar S, Kohli V, et al. Potent anti-inflammatory activity of ursolic acid, a triterpenoid antioxidant, is mediated through suppression of NF- $\kappa$ B, AP-1 and NF-AT. PloS One 2012;7:e31318.

37. Zheng QY, Li PP, Jin FS, Yao C, Zhang GH, Zang T, et al. Ursolic acid induces ER stress response to activate ASK1-JNK signaling and induce apoptosis in human bladder cancer T24 cells. Cell Signal 2013;25:206-13.

38. Lewinska A, Adamczyk Grochala J, Kwasniewicz E, Deregowska A, Wnuk M. Ursolic acid-mediated changes in glycolytic pathway promote cytotoxic autophagy and apoptosis in phenotypically different breast cancer cells. Apoptosis 2017;22:800-15.

39. Lee YH, Wang E, Kumar N, Glickman RD. Ursolic acid differentially modulates apoptosis in skin melanoma and retinal pigment epithelial cells exposed to UV-VIS broadband radiation. Apoptosis 2014;19:816-28. 
40. Lin CN, Gan KH. Antihepatotoxic principles of solanum capsicastrum. Planta Med 1989;55:48-50.

41. Gutierrez Rebolledo GA, Siordia Reyes AG, Meckes Fischer M Jimenez Arellanes A. Hepatoprotective properties of oleanolic and ursolic acids in antitubercular drug-induced liver damage. Asian Pac J Trop Med 2016;9:644-51.

42. Li JS, Wang WJ, Sun Y, Zhang YH, Zheng L. Ursolic acid inhibits the development of nonalcoholic fatty liver disease by attenuating endoplasmic reticulum stress. Food Funct 2015;6:1643-51.

43. Liobikas J, Majiene D, Trumbeckaite S, Kursvietiene L, Masteikova R, Kopustinskiene DM, et al. Uncoupling and antioxidant effects of ursolic acid in isolated rat heart mitochondria. J Nat Prod 2011;74:1640-4.

44. Dong $\mathrm{X}$, Liu S, Zhang L, Yu S, Huo L, Qile $\mathrm{M}$, et al. Downregulation of mił2 1 is involved in direc $t$ actions of ursolic acid on the heart: implications for cardiac fibrosis and hypertrophy. Cardiovasc Ther 2015;33:161-7.

45. Li L, Zhang X, Cui L, Wang L, Liu H, Ji H, et al. Ursolic acid promotes the neuroprotection by activating Nrf2 pathway after cerebral ischemia in mice. Brain Res 2013;1497:32-9.

46. Ding H, Wang H, Zhu L, Wei W. Ursolic acid ameliorates early brain injury after experimental traumatic brain injury in mice by activating the Nrf2 pathway. Neurochem Res 2017;42:33746.

47. Singh A, Venugopala KN, Khedr MA, Pillay M, Nwaeze KU, Coovadia Y, et al. Antimycobacterial, docking and molecular dynamic studies of pentacyclic triterpenes from Buddleja saligna leaves. J Biomol Struct Dyn 2017;35:2654-64.

48. Do Nascimento PG, Lemos TL, Bizerra A, Arriaga A, Ferreira DA, Santiago GM, et al. Antibacterial and antioxidant activities of ursolic acid and derivatives. Molecules 2014;19:1317-27.

49. Wang YL, Wang ZJ, Shen HL, Yin M, Tang KX. Effects of artesunate and ursolic acid on hyperlipidemia and its complications in rabbit. Eur J Pharm Sci 2013;50:366-71.

50. Wang L, Wang GL, Liu JH, Li D, Zhu DZ, Wu LN. Effects of ursolic acid in ameliorating insulin resistance in liver of KKAy mice via peroxisome proliferator-activated receptors $\alpha$ and $\gamma$. Chin J Intgr Med 2012;10:793-9.

51. Castro AJ, Frederico MJ, Cazarolli LH, Mendes CP, Bretanha LC Schmidt EC, et al. The mechanism of action of ursolic acid as insulin secretagogue and insulinomimetic is mediated by crosstalk between calcium and kinases to regulate glucose balance. Biochim Biophys Acta 2015;1850:51-61.

52. Mahlo SM, McGaw LJ, Eloff JN. Antifungal activity and cytotoxicity of isolated compounds from leaves of breonadia salicina. J Ethnopharmacol 2013;148:909-13.
53. Shaik AB, Ahil SB, Govardhanam R, Senthi M, Khan R, Sojitra R, et al. Antifungal effect and protective role of ursolic acid and three phenolic derivatives in the management of sorghum grain mold under field conditions. Chem Biodivers 2016;13:1158-64.

54. Zhao J, Chen J, Liu T, Wan J, Zhao J, Li W, et al. Anti-viral effects of ursolic acid on guinea pig cytomegalovirus in vitro. J Huazhong Univ Sci Technol 2012;32:883-7.

55. Kong L, Li S, Liao Q, Zhang Y, Sun R, Zhu X, et al. Oleanolic acid and ursolic acid: Novel hepatitis $C$ virus antivirals that inhibit NS5B activity. Antiviral Res 2013;98:44-53.

56. US EPA, Estimation program interface (EPI) Suite. Ver. 4.0.; 2009. Available from: http://www.epa.gov/oppt/exposure/pubs/episuitedl.htmapu dPubChem. [Last accessed on 10 Nov 2009]

57. Shazly GA, Ibrahim MA, Badran MM, Zoheir KMA. Utilizing pluronic F-127 and gelucire 50/13 solid dispersions for enhanced skin delivery of flufenamic acid. Drug Dev Res 2012;73:299-307.

58. Maulvi FA, Dalwadi SJ, Thakkar VT, Soni TG, Gohel MC, Gandhi TR. Improvement of dissolution rate of aceclofenac bysolid dispersion technique. Powder Technol 2011;207:47-54.

59. Kadian RE. Nanoparticles: a promising drug delivery approach. Asian J Pharm Clin Res 2018;11:30-5

60. Wadhwa A, Mathura V, Lewis SA. Emerging novel nanopharmaceuticals for drug delivery. Asian J Pharm Clin Res 2018;11:35-42.

61. Qushawy MO, Nasr A. Solid lipid nanoparticles as nano drug delivery carriers: Preparation, characterization and application. Int J Appl Pharm 2020;12:1-9.

62. He Q, Guo S, Qian Z, Chen X. Development of individualized anti-metastasis strategies by engineering nanomedicines. Chem Soc Rev 2015;44:6258-86.

63. Khadka P, Ro J, Kim H, Kim I, Kim JT, Kim-- H.; Cho, J. M.;Yun, G.; Lee, J. Pharmaceutical particle technologies: an approach to improve drug solubility, dissolution and bioavailability. Asian J Pharm Sci 2014;9:304-16.

64. Osmani RA, Aloorkar NH, Kulkarni AS, Harkare BR, Bhosale RR. A new cornucopia in topical drug delivery: microsponge technology. Asian J Pharm Sci Technol 2014;4:48-60.

65. Baricevic D, Sosa S, Della Loggia R, Tubaro A, Simonovska B, Krasna A, et al. Topical anti-inflammatory activity of Salvia officinalis L. leaves: the relevance of ursolic acid. J Ethnopharmacol 2001;75:125-32.

66. Vasconcelos T, Sarmento B, Costa P. Solid dispersions as strategy to improve oral bioavailability of poor water soluble drugs. Drug Discovery Today 2007;12:23-4. 